\title{
Envelhecimento: significado para idosos encarcerados
}

\author{
Aging: meaning for incarcerated elderly
}

Lannuzya Veríssimo de Oliveiral

Gabriela Maria Cavalcanti Costa ${ }^{2}$

Kaio Keomma Aires Silva Medeiros'

\section{Resumo}

Objetivo: Compreender o significado do envelhecimento para idosos encarcerados. Método: Estudo descritivo, com abordagem qualitativa, realizado entre os meses de julho e dezembro de 2011, com idosos reclusos no sistema penitenciário do Estado da Paraíba. A amostra foi encerrada em 11 sujeitos, com auxílio da técnica de saturação das informações. Para coleta de dados, utilizaram-se um formulário sociodemográfico e entrevista semiestruturada. Conduziu-se a análise dos discursos sob a ótica da Análise de Conteúdo. Resultados: Verificou-se predominância de idosos na faixa-etária entre 60 e 65 anos, casados, com média de seis filhos, católicos, possuidores de algum tipo de renda, alfabetizados, com média de confinamento de três anos e regularidade no recebimento de visita. Após a análise dos discursos, conformaram-se as categorias: significado do envelhecimento para idosos e ser idoso encarcerado. Conclusões: O significado do envelhecimento para idosos encarcerados relaciona-se a sentimentos de melancolia, angústia e constantes perdas, bem como pela impossibilidade de qualquer tipo de desenvolvimento. A dificuldade para exercer atividade laboral, a diminuição do convívio familiar e os conflitos intergeracionais corroboram a perda da qualidade de vida dos idosos no cárcere. As significações negativas quanto ao envelhecimento encontradas neste estudo assemelham-se as dos idosos libertos, porém são evidenciadas e, por vezes, potencializadas pelo encarceramento.

\section{Abstract}

Objective: To understand the meaning of aging for elderly prisoners. Methods: A descriptive study with qualitative approach conducted between July and December 2011with elderly inmates in the prison system of Paraiba state. The sample was terminated with the help of the saturation technique of information in 11 subjects. For data collection a socio-demographic form and a semi-structured interview was used. It was carried out the discourse analysis from the viewpoint of Content Analysis. Results: There was a predominance in the elderly age group between 60 to 65 years old, married, with an
Palavras-chave:

Envelhecimento. Idoso.

Prisões. Prisioneiros.
Key words: Aging. Elderly. Prisons. Prisoners.

\footnotetext{
1 Departamento de Enfermagem. Universidade Estadual da Paraíba. Campina Grande, PB, Brasil.

2 Departamento de Enfermagem, Programa de Pós-graduação em Saúde Pública. Universidade Estadual da Paraíba. Campina Grande, PB, Brasil.
} 
average of six children, Catholics, possessing some kind of income, literacy, with an average of three years confinement and regularity in receiving visits. After analyzing the discourse, categories were conformed. Meaning of aging for seniors and elderly being incarcerated. Conclusions: The meaning of aging for incarcerated elderly relates to feelings of melancholy, anxiety and constant losses, as well as the impossibility of any type of development. The difficulty to perform labor activity, the decrease from family life and intergenerational conflicts corroborate the loss of quality of life for seniors in jail. The negative meanings regarding aging in this study are similar to those of freed elderly, but are highlighted and sometimes enhanced by incarceration.

\section{INTRODUÇÃOO}

A sociedade contemporânea vem experimentando profundas e radicais transformações no contexto das práticas sociais e no estilo de vida das pessoas e grupos. Dentre essas transformações, o envelhecimento das populações se destaca como fator significativo no âmbito da saúde pública global. ${ }^{1}$

Ao longo do século XX, a expectativa de vida da população mundial aumentou em aproximadamente 30 anos. No Brasil, especificamente, entre os anos de 1997 e 2007, a população em geral apresentou crescimento relativo da ordem de $21,6 \%$, ao passo que a geriátrica mais que dobrou, com aumento de aproximadamente $47,8 \%{ }^{2}$

Atento a tais modificações demográficas, bem como às implicações sociais que estas acarretam, o Estado buscou atender às demandas da população idosa, o que culminou com a instituição do Estatuto do Idoso, em 2003, que preconiza os direitos dos idosos e as estratégias a serem desenvolvidas pelas instituições e pelos atores sociais comprometidos com o bem-estar desses indivíduos. Por justificativas semelhantes, foi estabelecida, em 2006, a Política Nacional de Saúde da Pessoa Idosa, por meio do Decreto $n^{\circ}$ 2.528 que estabelece diretrizes para o cuidado do idoso na atenção básica.

Verifica-se, entretanto, que por vezes a preocupação com os idosos se detém na prevenção das doenças crônicas que usualmente os acometem, em detrimento da qualidade plena da vida, a qual só pode ser alcançada por meio do conhecimento acerca das reais necessidades que os idosos apresentam. Acredita-se que um caminho para compreender tais idiossincrasias é buscar apreender o significado do envelhecimento para esses indivíduos. ${ }^{3}$

Tal significado tem sido permeado de estereótipos e crenças desde a Antiguidade, nas quais o envelhecimento é compreendido como um processo degenerativo e oposto a qualquer desenvolvimento. ${ }^{4}$ Talvez por isso, diversos estudos que objetivaram desvelar o significado do envelhecimento para determinados grupos de pessoas tenham encontrado significações negativas quanto a ele.

É possível que tais significações estejam presentes no ambiente prisional, pois se idosos inseridos em um contexto social favorável têm alguns aspectos de seu envelhecimento mal compreendidos, e consequentemente negligenciados, acredita-se que no contexto do encarceramento essas dificuldades são ainda mais agravadas, visto que o sistema prisional brasileiro é reconhecidamente deficiente no que concerne às condições de higiene, saúde, disciplina e variedade cultural. ${ }^{5}$

Embora algumas carências relacionadas à saúde da população carcerária tenham sido contempladas com previsão de atividades e metas, na publicação do Plano Nacional de Saúde no Sistema Penitenciário (PNSSP), em 2003, o documento norteador das práticas no cenário não faz menção a ações específicas direcionadas ao público idoso, focando suas atenções na população jovem e nas condições de morbi-mortalidade mais incidentes e prevalentes naquele cenário. ${ }^{6}$ 
Por tais constatações, acredita-se na pertinência deste estudo, devido a sua aplicação prática no direcionamento de políticas de saúde pública no ambiente prisional. Ademais, estudos sobre envelhecimento e saúde dos idosos foram temáticas recomendadas pelo Ministério da Saúde com a publicação da Agenda Nacional de Prioridades de Pesquisa em Saúde.?

Mediante tais considerações, o objetivo desta pesquisa foi compreender o significado do envelhecimento para idosos encarcerados.

\section{MÉTODO}

Estudo descritivo, com abordagem qualitativa, realizado entre os meses de julho e dezembro de 2011, em seis unidades prisionais subordinadas à Secretaria de Administração Penitenciária do Estado da Paraíba (SEAP), classificadas como penitenciárias e/ou presídios, que possuíam unidades de saúde implantadas conforme prevê o PNSSP.

O número de sujeitos que constituiu a amostra foi determinado com base no critério de saturação das informações. Desse modo, concluiu-se a coleta com 11 entrevistas, adotando-se os critérios de inclusão: estar recluso a um período superior a seis meses; cumprir pena em regime fechado; possuir idade igual ou superior a 60 anos; ser detentor de um nível de comunicação satisfatório; não possuir nenhuma afecção que comprometa sua capacidade cognitiva e/ou impossibilite a aplicação do instrumento de pesquisa; e aceitar participar do estudo, assinando o Termo de Consentimento Livre e Esclarecido (TCLE).

As unidades prisionais foram inicialmente visitadas para conhecer a rotina dos detentos e convidá-los a participar do estudo; posteriormente, foi viabilizada a coleta considerando a comodidade e a conveniência do sujeito, da instituição e dos pesquisadores. Em encontros individuais e sob escolta de agentes penitenciários, como prevê a rotina dos serviços, aplicou-se um formulário sociodemográfico para caracterizar os sujeitos, contendo questões referentes à idade, situação conjugal, crença religiosa, nível de escolaridade, dados clínicos, assistência à saúde, tempo de confinamento e recebimento de visitas. Em seguida foi realizada uma entrevista semiestruturada abordando questões referentes ao significado do envelhecimento.

Os discursos obtidos foram analisados à luz da Análise de Conteúdo. ${ }^{8}$ Dessa forma, realizou-se a pré-exploração do material coletado, a seleção de unidades de análise e, por fím, o processo de categorização e subcategorização.

Por questões ético-legais, o estudo foi encaminhado, para avaliação e parecer, ao Comitê de Ética em Pesquisa da Universidade Estadual da Paraíba (CEP-UEPB), atendendo ao disposto na Resolução no 196/96 do Conselho Nacional de Saúde (CNS). Sua execução se deu somente após a aprovação pelo referido comitê, conforme protocolo no 0400.0.133.000-09.

\section{RESULTADOS E DISCUSSÃO}

\section{Caracterização dos sujeitos}

Dentre os 11 idosos entrevistados, sobressaiu a faixa-etária de 60 a 65 anos, predominando casados, com média de seis filhos, católicos e alfabetizados. No que se refere à renda, a maioria era beneficiada, quer por aposentadoria, quer por exercer atividades laborais na instituição prisional. A hipertensão e o diabetes se destacaram entre as doenças mais prevalentes, seguidas de gastrite. Todos os entrevistados, no entanto, relataram possuir acesso ao Sistema Único de Saúde (SUS) por meio das unidades de saúde instaladas nos respectivos presídios e/ ou fora deles. Em relação às visitas de familiares e amigos, a maioria as recebia. A média de confinamento foi de três anos.

\section{Categorias de análise}

A análise dos discursos que emergiram nas entrevistas convergiu em duas categorias, que foram: "significado do envelhecimento para idosos" e "ser idoso encarcerado". 


\section{Significado do envelhecimento para idosos}

Apreendeu-se que para os participantes deste estudo envelhecer significa uma vivência permeada pelo cansaço e limitações.

"Eu vejo o idoso como uma pessoa cansada, já que não tem certo tratamento, alimentação necessária... Cada vez vai ficando pior!” (2I- $\alpha)$.

"A gente vai afracando, né? Não é aquela pessoa como era há vinte, trinta anos atrás, né? Nós vai ficando velho, vai afracando, vai amolecendo, cada dia que passa pra frente o cara só vai diminuindo!" (4II- $\beta$ ).

No imaginário social, sobretudo das sociedades ocidentais, a condição do idoso é associada ao desgaste, às limitações crescentes e a perdas físicas. ${ }^{9}$ Esta compreensão converge com os discursos dos sujeitos, os quais referenciam o envelhecimento de forma negativa, semelhante a idosos libertos.

É possível que as condições inerentes ao estado de confinamento, a exemplo de não dispor de uma alimentação necessária, conforme relatado, contribuam para que as limitações impostas naturalmente pelo processo de envelhecimento sejam evidenciadas com maior facilidade no cárcere. Quando o corpo não dispõe de um suprimento nutricional que atenda a suas demandas metabólicas, ele funciona inadequadamente, acarretando debilidade física e cansaço, agravando as características fisiológicas do envelhecimento. ${ }^{10}$

Assim sendo, os idosos necessitam de uma avaliação pautada no conhecimento do processo de envelhecimento e de suas peculiaridades, adaptadas à realidade sociocultural na qual eles estão inseridos ${ }^{11,12}$ - neste caso, o sistema prisional. Acerca disto e na tentativa de desvelar aspectos relativos ao referido processo, os discursos que seguem demonstram ser o envelhecimento, no entendimento dos sujeitos deste estudo, um fenômeno biológico, cíclico e culturalmente elaborado.

"Isso é da vida... A gente tem que ficar velho mesmo! Você compra um carro novo, ele fica velho e independente do que você faça se acaba!" (3V-2).
"É o cabra se conformar que tá velho se aquietar e pronto. Esperarpelo dia de morrer! Cabou-se! Esperar pela morte e pronto. Daqui pra frente o cabra não tem outra opcão não, é só esperar o dia de morrer, já tá vencido." $(6 I V-\beta)$.

Nas falas dos participantes, o envelhecer é também entendido como sinônimo de decadência, numa clara manifestação de autodiscriminação e descartabilidade. O ciclo biológico culmina com o envelhecimento, que se expressa pelos sinais externos do corpo, anunciando a proximidade com o final da vida. Nesse sentido, e por ser a morte uma experiência inevitável, inequívoca e universal, os discursos acerca do envelhecimento geralmente são permeados por sensação de desânimo mediante a iminência da finitude..$^{13}$

Compreendê-lo - o envelhecimento - como um processo natural ao longo da vida é uma das formas de vivê-lo em harmonia, aceitando as limitações que a velhice proporciona ${ }^{14}$ e que são evidenciadas durante o confinamento. Isso porque, quando recolhidas aos estabelecimentos prisionais, as pessoas trazem problemas de saúde, vícios, bem como transtornos mentais, que são gradualmente agravados pela precariedade das condições de moradia, alimentação e saúde do cárcere. $^{5}$

O adoecimento, especificamente, modifica a rotina dos indivíduos e corrobora a perda da qualidade de vida. $^{15}$ Percebe-se, por meio dos discursos que seguem, que para os idosos encarcerados há forte associação entre envelhecimento e enfermidades, não se concebendo a possibilidade de um envelhecimento saudável.

"O ruim de envelhecer, de ser idoso, é só a saúde que fica comprometida... entra em decadência!" (2I-a)

"É isso mesmo que eu lhe disse doutor, eu não me sinto idoso, se colocar na cabeça que é idoso aí vou andar de bengala, ter que pedir ajuda aos meus filhos pra me levar ao banbeiro, e vou ficar só em cima da cama." (8II-a)

Acredita-se que os problemas de saúde decorrentes das condições de confinamento não têm sido objeto de ações que possibilitem o acesso 
das pessoas presas à saúde de forma integral e efetiva. ${ }^{5}$ Acrescente-se a isto, os problemas de saúde típicos dessa fase da vida, os chamados "Gigantes da Geriatria" - insuficiência cerebral; instabilidade de postura e quedas; imobilidade; incontinência - que contribuem, direta e indiretamente, para isolar o idoso e diminuir sua qualidade de vida. ${ }^{16}$

\section{Subcategoria: desvalorização}

Observam-se também, na fala dos idosos, sentimentos de desvalorização social e conformismo frente às adversidades, representadas por doenças e/ou limitações.

"Acho que o valor do velho éponco." (3V-2).

"Se en pudesse voltar a minha idade, há vinte anos atrás, en voltaria! Mas num pode, aí tem que se conformar mesmo, não tem outra opção." (6IV- $\beta)$.

Historicamente, as sociedades reagiram aos seus membros idosos de diversas formas, ora respeitando-os, ora discriminando-os. Em se tratando das sociedades produtivistas, os idosos tendem a ser segregados e desvalorizados. ${ }^{10}$

No âmbito prisional, não somente a condição de idoso os credita a uma notória discriminação, como também o fato de a população carcerária ser composta, majoritariamente, de pobres, analfabetos e de indivíduos sem profissão definida, o que já caracteriza uma situação de exclusão social que precede o aprisionamento. ${ }^{5}$

Assim sendo, crê-se que o idoso encarcerado vivencia, no mínimo, três circunstâncias excludentes e discriminatórias em suas vidas: velhice, precárias condições sociais e, finalmente, a prisão. Portanto, inegavelmente excluídos da sociedade, a qual tende a valorizar o perfil ágil, vigoroso, belo, sexual, saudável, atraente e produtivo dos jovens. ${ }^{15,17}$ Os idosos entrevistados parecem ter dificuldades em aceitar a velhice, o que culmina com a rejeição das modificações físicas decorrentes dessa fase da vida, como observamos nos discursos:

\author{
"Eu me vejo igual aos outros, não vejo diferença \\ nenbuma!" (10III- $\beta)$. \\ "Eu não me sinto idoso... por causo do que en sou \\ jovem de tipo..." (8II-a)
}

É bem verdade, que nas situações em que o envelhecimento é aceito como um êxito, o aproveitamento da competência, experiência e dos recursos humanos dos grupos mais velhos é assumido com naturalidade, como uma vantagem para o crescimento de sociedades humanas maduras e plenamente integradas. ${ }^{11}$ Entretanto, isso parece não ser considerado quando se trata de idosos encarcerados, pois os mesmos tentam evitar a classificação de velhice.

\section{Subcategoria: maturidade}

Compreender e vivenciar o envelhecimento, de forma positiva ou negativa, está atrelado, entre outros fatores, ao modo como os idosos se percebem e constroem o seu envelhecer. ${ }^{18}$ Nos discursos que se seguem, os idosos extraem do envelhecimento sentimentos positivos:

"É um processo de lapidação, né? Porque o idoso, com a vida percorrida, com a qual você adquire knowhow, comportamento, como lidar com as pessoas... Envelhecer é um processo de lapidação e nesse processo todo existem aqueles que conseguem crescer!" (5 I-a).

"Envelhecer é amadurecer, é ter mais solidez, ter mais firmeza, mais contundência, mais certeza, mais confiança, mais fé, mais sabedoria, né?" (7 IV- $\beta$ ).

Percebe-se a utilização de processos interativos para construir significados às situações vivenciadas. Ao (res)significar as próprias vivências, o sujeito constrói um modelo de "idoso ideal" que corresponde àquele conformado com seu momento presente, bem-humorado, fácil de lidar, comunicativo e que não estabelece impedimentos a sua interação com outrem.

Nesse sentido, acredita-se que é por meio da utilização de um quadro de referências pessoais para a identificação e interpretação das situações vivenciadas outrora, que os sujeitos conseguem 
comparar a vivência passada com a atual para dar um novo sentido a sua vida. ${ }^{19}$

\section{Ser idoso encarcerado}

Verifica-se que mesmo em grupos com características homogêneas o significado do envelhecimento difere entre os indivíduos, devido às imposições sociais, culturais ou relacionadas à subjetividade de cada idoso. ${ }^{20}$ Até o momento, os discursos dos sujeitos desvelaram características deste significado propriamente dito e, a partir de agora, as falas revelam as implicações do envelhecimento no cárcere:

"É melhor morrer, do que está dentro de uma joça dessa!" (2I-a).

"Eu acho que não é bom pra ninguém, viu doutor? Mas, pra idosos, é mais pior!" (9III- $\beta$ ).

"Fora é melhor, dez mil vezes! Aqui aumenta mais o envelhecimento! A justiça é pra ser mais dos idosos, o idoso não pode estar assim e tal!" (10III- $\beta$ ).

Para esses idosos, a prisão parece acentuar as dificuldades que acompanham o envelhecimento, mas pode-se concluir, também, que o cárcere não é deficiente somente no atendimento à demanda dos idosos. Aspectos como práticas de violência, precariedade de espaço físico e na carência do atendimento à saúde compõem uma realidade vivenciada pela maioria dos encarcerados, idosos ou não.

É consenso que o sistema penitenciário brasileiro é vergonhoso e demasiadamente deficiente em sua estrutura e ações, ${ }^{21}$ condições essas que determinam sobremaneira a vulnerabilidade das pessoas confinadas. ${ }^{22}$ Compreende-se, portanto, a prisão como um espaço onde apenas os fortes sobrevivem, força não só física, mas também emocional, bem como aquela que se manifesta na hierarquia organizacional de cada instituição prisional. ${ }^{23}$

Embora a força seja subjetiva tanto quanto o seu antônimo, a fraqueza, pressupõe-se que o envelhecimento traz consigo a fragilidade corporal, e por vezes, o enfraquecimento emocional. ${ }^{15,24}$ Por esse motivo, crê-se que o ambiente prisional, hoje deveras ultrapassado e centrado, sobretudo na punição, deve ser planejado com vistas a atender às demandas desses indivíduos, resguardando, inclusive, direitos fundamentais à cidadania.

As significações encontradas a respeito do envelhecimento na prisão representam, antes de tudo, diferenças construídas de acordo com a história de vida de cada sujeito. Talvez por isso, e embora não reflitam a maioria dos discursos encontrados, apreenderam-se aqueles que representam algo de positivo do envelhecer, ainda que em confinamento, como se verifica no relato que segue:

"Quer dizer, de certa forma, apesar das condições de confinamento eu me sinto bem, quer dizer, eu vivo harmonicamente, com DEUS com os apenados..." (5I-a).

\section{Subcategoria: ambiente insalubre como fator predisponente ao adoecimento}

Dentre os fatores limitantes à qualidade de vida dos idosos, certamente a doença é aquele que mais influencia a capacidade de adaptação e reserva funcional para o desempenho de atividades. As doenças, além de se encarregarem de estabelecer incapacidades no âmbito do domínio físico, mental, psicológico e socioeconômico, também se encarregam de frustrar o prazer das pessoas no que concerne ao seu estilo de vida. ${ }^{14}$ Para muitos idosos, o ambiente prisional é um fator promotor do adoecimento:

\footnotetext{
"Tá vendo essa gritaria aí? Sobe a pressão! Sobe tudo! Como é que a pressão do cara baixa em um lugar como esse?" (3V-D).
}

"Eu sou asmático, é falta de ar toda vida, aquele frio de madrugada! O colchão é só a capa, bem fininho!" (10 III- $\beta$ ).

Conforme demonstram os discursos, a insalubridade da prisão contribui para o adoecimento ou dificulta a manutenção e restabelecimento da saúde. Entenda-se saúde de forma ampla, 
perpassando uma mera questão de assistência médica e de acesso a medicamentos. ${ }^{25}$

Idosos são indivíduos reconhecidamente necessitados de uma atenção mais qualificada e intensificada em saúde. ${ }^{1,13}$ Quando se trata do ambiente prisional, essas necessidades são maiores, mas, no entanto, menos atendidas, se considerarmos as condições já discutidas anteriormente.

A constatação de ambiente insalubre pelos idosos encarcerados reforça deficiências de um sistema penal brasileiro cujo caráter é fortemente punitivo, haja vista que a pena é muitas vezes considerada como vingança da sociedade para com a pessoa infratora. Isso dificulta em muito a prática consolidada dos direitos humanos de indivíduos detentos, inclusive no resgate a sua cidadania. ${ }^{26}$

Em reconhecimento à insalubridade de que trata a presente subcategoria de análise, bem como sua relação direta com o aparecimento de doenças nas populações carcerárias, a execução do PNSSP, cujo foco, em linhas gerais, é a garantia de uma assistência em saúde integral de qualidade, esbarra em alguns impasses, como o financiamento, à dificuldade de compatibilização da lógica da segurança com a da saúde pública, bem como de contratação de todos os componentes das equipes de saúde no sistema penitenciário. ${ }^{27}$ Tal fato tem um fundo histórico, haja vista que a questão da atenção à saúde da população encarcerada no Brasil tem sido feita sob uma ótica reducionista, na medida em que as ações desenvolvidas limitamse àquelas voltadas para DST/Aids, redução de danos associados ao uso abusivo de álcool e outras drogas e imunizações. ${ }^{6}$

No que tange ao idoso preso, percebem-se lacunas ainda maiores quanto a aspectos de sua saúde, visto que as características fisiológicas desses indivíduos os tornam mais vulneráveis as doenças recorrentes no ambiente prisional, a exemplo da tuberculose, ${ }^{28}$ havendo, portanto, a necessidade de implementar ações de saúde no ambiente prisional que reconheçam as particularidades/necessidades do idoso.
Atente-se ainda que o ambiente prisional se torna insalubre por dificultar o convívio familiar, visto que é consenso na comunidade científica que a permanência do idoso em seus núcleos familiares e comunitários contribui para seu bem-estar. ${ }^{29}$ Convergindo com estas assertivas, no discurso que segue, percebe-se o sofrimento dos sujeitos decorrentes da diminuição do convívio familiar :

"Mas en sinto muita falta da liberdade, da minha familia, porque ela não pode vir toda semana aqui... não tenho uma comunicação direta, e isso é muito ruim." (1I-a).

Sabe-se que as relações afetivas/familiares são indispensáveis na manutenção da saúde dos indivíduos, mas há de se pensar na capacidade de as prisões receberem as famílias dos apenados. Um ambiente que, na percepção do idoso preso, não é saudável, certamente não o será para seus familiares. Decerto, somente assegurar por meio da lei o direito a visitas não é o suficiente para que o idoso o usufrua plenamente. Ademais, o modelo da família contemporânea, que possui como características a mobilidade, o tamanho reduzido, a fragilidade nos laços matrimoniais e o distanciamento entre os parentes, favorece a diminuição do sentido de responsabilidade no cuidado aos idosos. ${ }^{30}$

O sentimento de vergonha, ao se dirigir a um estabelecimento penal para visitar um parente; aguardar nas longas filas; as revistas (pessoais e de objetos); o tratamento inadequado que muitas vezes recebem por parte do servidor penitenciário; o desassossego que a todo instante envolve o local; e o incômodo em perceber as dificuldades manifestadas por seus parentes corroboram a diminuição do número de visitas aos apenados e, consequentemente, dificultam o convívio familiar. ${ }^{31,32}$

Outrossim, acredita-se que o ambiente prisional é insalubre também por dificultar o exercício laboral. Com ou sem fins lucrativos, o trabalho identifica a função social de um sujeito, por meio da qual os indivíduos são respeitados e mantêm sua autonomia frente à comunidade. ${ }^{33}$ 
Por esse motivo, os indivíduos referem em seus discursos que a dificuldade em exercer uma função nas unidades prisionais se configura em uma grande perda:

"É muito ruim! O cara acostumado a trabalhar, viver sem precisar dos outros... Como é que eu vou ajudar a familia? Eu criei filhos, que agora são pais de família, mas não precisava deles! Agora eu preciso! É muito ruim... O cara acostumado a trabalhar, $e$ ficar aqui...” (3V-z).

"Fora é melhor dez mil vezes... Quer comparar o negócio fora com aqui dentro... sente falta de familia, de trabalho, não gosto de ficar parado!" (11III- $\beta$ ).

O trabalho nas prisões permite manter a autonomia, além de garantir remissão de pena e afastar a inércia, favorecendo também o convívio social, ${ }^{34}$ sobretudo em indivíduos idosos que sentem a necessidade de manter sua autonomia e capacidade de decisão sobre as situações do cotidiano, sendo esta condição primordial para a manutenção da qualidade de vida. ${ }^{19}$

Nessa perspectiva, acredita-se que os idosos inseridos no âmbito prisional são privados não apenas da liberdade, mas, também, de parte da sua autonomia, na medida em que a eles quase nunca é permitido exercer uma atividade laboral. Esse é um fator a ser considerado, pois saúde não se restringe ao controle e à prevenção de agravos e doenças, mas à interação entre a saúde física, a saúde mental, a independência financeira, a capacidade funcional e o suporte social. ${ }^{35}$

\section{Subcategoria: dificuldade na convivência intergeracional}

A convivência humana, embora essencial, não configura tarefa fácil. São comuns as tensões, conflitos e dissabores, sobretudo entre as distintas gerações. Nas falas que seguem, fica perceptível a dificuldade de interação entre os jovens e os idosos presos:

"Fico perto dos velhos, conversando com os idosos ali! Porque jovem é jovem, não quer conversa com os idosos, né?" (10III- $\beta)$.

\begin{abstract}
"Envelhecer no presídio não é bom! Porque a gente tá com a idade avançada, ai ficam no meio da molecada... Tem que saber levar a vida no meio dos jovens." (1I-a).

[...] "viver com esse povo novo é difícil, tem que estar em um canto quieto! O cara diz logo: "é velho...é velho...' Não tem jeito, você entende como é o negócio! Ai fica difícil!" (3V-D).

[...] "é difícil viver com jovens, viver porque é o jeito mesmo, né? Mas não é bom não! A pessoa ser novo, jovem, era pra ser separado...” (11III- $\beta)$.
\end{abstract}

Desde os tempos mais remotos, envelhecer exige um ritual por meio do qual a sociedade adulta procura separar os idosos da sua convivência, reservando-se a prática de manter incluso em seu meio aqueles reconhecidamente capazes de solucionar os conflitos enfrentados pelos mais jovens que os substituirão no governo da comunidade e de manter o equilíbrio necessário à organização social. ${ }^{13}$

Acredita-se também que, devido ao declínio da função física, os idosos podem ter menos energia para investir na interação social, ${ }^{10}$ a qual parece ser prejudicada, e às vezes até impossibilitada, devido aos desencontros comuns entre gerações.

\section{CONCLUSÕES}

O significado do envelhecimento para idosos encarcerados relaciona-se a sentimentos de decadência, finitude, adoecimento, cansaço e desvalorização social. Apreenderam-se expressões de negação quanto à condição de ser idoso, semelhantes às encontradas fora do ambiente prisional, bem como referências positivas quanto ao amadurecimento possibilitado pelo envelhecer.

Compreende-se a prisão como um ambiente insalubre para os idosos, sobretudo pela existência de condições agravantes inerentes ao encarceramento, tais como: desvalorização social, diminuição no convívio familiar, dificuldade no exercício de atividade laboral, conflitos que permeiam a convivência intergeracional, bem como a insalubridade das unidades prisionais. 
Acrescentem-se, a esses aspectos, as incapacidades próprias do envelhecer que inevitavelmente alcançam idosos encarcerados, culminando, pois, para uma maior necessidade de promoção e proteção à saúde. Apesar de não se restringirem a idosos presos, tais incapacidades parecem ser evidenciadas com mais facilidade e, às vezes, até potencializadas, pelo encarceramento.

Considerando que a pesquisa desenvolvida representa um avanço no conhecimento quanto aos idosos encarcerados, sobretudo pela escassez de estudos com tal abordagem, percebe-se a necessidade de adequações nas políticas públicas de saúde que contemplem ações mais resolutivas para o grupo social objeto desta pesquisa, tais como: atividades educativas, de lazer, bem como de integração social. Devem ser implantadas e/ou intensificadas, também, ações de ressocialização, buscando a participação dos familiares na vida do idoso encarcerado, bem como um suporte adequado

\section{REFERÊNCIAS}

1. Ministério da Saúde (Brasil). Secretaria de Atenção à Saúde. Envelhecimento e Saúde da pessoa idosa. Série A. Normas e Manuais Técnicos. Caderno de Atenção Básica n. 19. Brasília: Ministério da Saúde, 2007. 192 p.

2. Instituto Brasileiro de Geografia e Estatística. Sinopse do censo demográfico 2010. [acesso em 29 abr 2012]. Disponível em: http://www.censo2010.ibge.gov.br/ sinopse/index.php

3. Freitas MC, Queiroz TA, Sousa JAV. O significado da velhice e da experiência de envelhecer para os idosos. Rev Esc Enferm USP 2010;44(2):407-12.

4. Reis PO, Ceolim MF. O significado atribuído a 'ser idoso' por trabalhadores de instituições de longa permanência. Rev Esc Enferm USP 2007;41(1):57-64.

5. Caixeta MC. Plano nacional de saúde no sistema penitenciário: análise do processo da sua implantação no Distrito Federal. [monografia]. Brasília: Universidade de Brasília, 2006.

6. Ministério da Saúde (Brasil). Portaria Interministerial n. 1.777, de 9 de setembro de 2003. [acesso em 29 abr 2012]. Disponível em: http://www.mj.gov.br/Depen/ funpen/legislacao/2003Portaria1777.pdf dos profissionais da saúde no atendimento a estes sujeitos, haja vista as peculiaridades que permeiam o envelhecimento na prisão.

Faz-se necessário planejar e executar estudos que contemplem o idoso no cárcere, sobretudo na área da saúde, cuja dinâmica de produção de informação sobre a matéria ainda se encontra deficiente. Por tal constatação, é pertinente recomendar a inclusão de temáticas relativas ao sistema penitenciário brasileiro entre aquelas pertencentes à Agenda Nacional de Prioridades de Pesquisa, como forma de estimular a construção do conhecimento nas referidas áreas, bem como ações focalizadas para a pessoa idosa no Plano Nacional de Saúde no Sistema Penitenciário (PNSSP).

As dificuldades em acessar dados sobre a população de idosos nos serviços; a escassez de estudos acerca da temática aqui abordada, na literatura geral das Ciências da Saúde e a insalubridade inerente ao encarceramento se constituíram em limitações desta pesquisa.

7. Ministério da Saúde (Brasil). Agenda Nacional de Prioridades e Pesquisa em Saúde. Série B. Textos Básicos em Saúde. Brasília: Ministério da Saúde, 2008. 68 p.

8. Bardin L. Análise de conteúdo. Lisboa: Edições 70; 2011. 279 p.

9. Guerra ACLC, Caldas CP. Dificuldades e recompensas no processo de envelhecimento: a percepção do sujeito idoso. Ciênc Saúde Coletiva 2010;15(6):2931-40.

10. Eliopoulos C. Enfermagem Gerontológica. Porto Alegre: Artmed; 2005.

11. Monteiro DMR. Espiritualidade e envelhecimento. In: Py L. et al. Percusos e dimensões psicossociais. Rio de Janeiro: NAU; 2004.

12. Jardim VCFS, Medeiros BF, Brito AM. Um olhar sobre o processo do envelhecimento: a percepção de idosos sobre a velhice. Rev Bras Geriatr Geronto 2006;9(2):25-34.

13. Riffiotis T. O ciclo vital contemplado: a dinâmica dos sistemas etários em sociedades negro-africanas. In: Barros ML. Velhice ou terceira idade? Estudos antropológicos sobre identidade, memória e política. Rio de Janeiro: Editora FGV; 2000. p. 27-35. 
14. Victor JF, Silva MJ, Araújo AR. O conceito de envelhecimento entre profissionais de saúde da família. Rev RENE 2002;3(2):71-6.

15. Teixeira SA. Produção e consumo social da beleza. Horiz Antropol 2001;7(16):189-220.

16. Silva MCS, Lautert L. O senso de auto-eficácia na manutenção de comportamentos promotores de saúde de idosos. Rev Esc Enferm USP 2010;44(1):61-7.

17. Nações Unidas. Plan de Acción Internacional de Madrid sobre el Envejecimento; 2002

18. Flores GC, Borges ZN, Denardin-Budó ML, Mattioni FC. Cuidado intergeracional com o idoso: autonomia do idoso e presença do cuidador. Rev Gaúcha Enferm 2010;31(3):467-74.

19. Oliveira, LV. Cabelos de neve na serra: verificando os riscos para depressão no idoso [monografia]. Campina Grande: Universidade Estadual da Paraíba; 2006.

20. Fernandes MGM; Garcia LG. O sentido da Velhice para Homens e Mulheres Idosos. Saúde e Sociedade 2010;19(4):71-783.

21. Moscogliato MA. HIV nos tribunais. Brasília: Ministério da Saúde, 1999. 85 p.

22. Pinese CSV. Análise do contexto funcional de uma penitenciária feminina com enfoque nas ações de enfermagem [monografia]. Ribeirão Preto: Escola de Enfermagem de Ribeirão Preto da Universidade de São Paulo; 2005.

23. Silva HGP, Souza LM, Mascarin MF. Prisão: só as fortes sobrevivem [monografia]. São João da Boa Vista: FAE; 2007.

24. Elias N. A solidão dos moribundos. Seguido de "Envelhecer e morrer". Rio de Janeiro: Jorge Zahar; 2001.

25. Alencar MSS, Leite ALI, Memoria SVF, Sousa JMS. Percepções dos profissionais da saúde da família a respeito da atenção à pessoa idosa em Teresina-PI. Rev Bras Geriatr Gerontol 2010;13(3):475-86.
26. Giordani AT. Violência sexual e a vulnerabilidade às IST-AIDS em mulheres detentas [tese de doutorado]. Ribeirão Preto: Escola de Enfermagem de Ribeirão Preto da Universidade de São Paulo; 2003.

27. Fundação Oswaldo Cruz (Brasil). Relatório do Projeto de Pesquisa "Do Plano à Política: garantindo o direito à saúde para todas as pessoas do sistema prisional”. Etapa 1: 01.01.2012 a 31.03.2012. Brasília: Escola Nacional de Saúde Pública; 2012.

28. Sánchez AR, Massari V, Gerhardt G, Barreto AW, Cesconi V, Pires J, et al. A tuberculose nas prisões do Rio de Janeiro, Brasil: uma urgência de saúde pública. Cad Saúde Pública 2007;23(3):545-52.

29. Camarano AA, Pasinato MT. O envelhecimento populacional na agenda das políticas públicas. In Camarano AA. Os novos idosos brasileiros muito alem dos 60? . Rio de Janeiro: IPEA; 2004. p. 253-292.

30. Scocuglia JBC. Cidade, habitus e cotidiano familiar. Campina Grande: Editora Universitária da UFPB; 2001.

31. Colmeia Z. Família e Cárcere - Os efeitos da punição sobre a unidade familiar e a necessidade de inclusão [monografia]. Boletim do Centro de Apoio Operacional das Promotorias Criminais, do Júri e de Execuções Penais. Área de Execução Penal 2011;86.

32. Oliveira GV. Sanção penal e família: diálogos e possibilidades [monografia]. Conselho Nacional de Política Criminal e Penitenciária; 2010.

33. Giatti L, Barreto SM. Saúde, trabalho e envelhecimento no Brasil. Cad Saúde Pública 2003;19(3):759-71.

34. Shikida PFA, Brogliatto SRM. O trabalho atrás das grades: um estudo de caso na Penitenciária Estadual de Foz do Iguaçu - PEF (PR). Rev Bras Gestão e Desenvol Reg 2008;4(1):128-54.

35. Ramos LR. Epidemiologia do envelhecimento. In: Freitas EV. Tratado de Geriatria e Gerontologia. Rio de Janeiro: Guanabara Koogan; 2000. 